\title{
The Role of the Primary Care Physician in Alzheimer's Disease
}

\author{
Hélène Villars ${ }^{1}$ and Bruno Vellas ${ }^{2}$
}

1. Hospital Practitioner; 2. Professor, Alzheimer's Disease Research and Clinical Centre, Toulouse University Hospital

\section{Abstract}

The increased incidence of Alzheimer's disease (AD) and related dementias in European and other northern countries is creating a real challenge for primary care providers. Primary care physicians (PCPS) must follow the general objectives of identifying dementia and allowing early diagnosis, disclosing diagnosis to both the patient and his or her family, preventing and treating, if possible, the complications of AD (falls, malnutrition and behavioural and psychological symptoms) and implementing a follow-up plan. It is essential for PCPS to develop interactions with specialist physicians and community professionals who intervene in the management of AD patients. The need for better education and training programmes for PCPS has been demonstrated in the literature in both the early diagnosis and management of AD. Clear guidelines specifically addressed to PCPS are needed.
\end{abstract}

\section{Keywords}

Alzheimer's disease, primary care physician, early diagnosis, disclosure, management, follow-up, support services, training programmes

\section{Disclosure: The authors have no conflicts of interest to declare.}

Received: 19 November 2010 Accepted: 17 January 2010 Citation: European Neurological Review, 2011;6(1):21-3 DOI:10.17925/ENR.2011.06.01.21

Correspondence: Hélène Villars, Alzheimer's Disease Clinical Research Centre, Gerontopôle, CHU Toulouse, Toulouse University Hospital, 170 Avenue de Casselardit, 31300 Toulouse, France. E: villars.h@chu-toulouse.fr

The increased incidence of Alzheimer's disease (AD) and related dementias in European and other northern countries is creating a real challenge for primary care providers. Providing care for AD patients is a long-term commitment on the part of the primary care physician (PCP). The PCP plays a key role in the management of older adults with $A D$ as both care provider and care planner., ${ }^{1,2}$ Indeed, such patients have complex medicopsychosocial needs and deserve specific management requiring a global approach. The role of PCPs is consolidated by the confidence of family care-givers in their skills. ${ }^{3}$ Clinical research also suggests that care-givers appreciate support from PCPS. ${ }^{4}$ In a recent article, neurodegenerative diseases, and especially $A D$, were identified as one of the main reasons for home visits in family medicine. ${ }^{5}$

A recent study has demonstrated that it is very difficult to collect information about the training and education of PCPs in the field of dementia. ${ }^{6}$ Some studies explore self-reported approaches and barriers in the management of patients with dementia. ${ }^{3,7.8}$ In primary care surveys exploring the tasks, knowledge and attitude of PCPS in dementia care management, one study has shown that the knowledge of PCPS was good, ${ }^{7}$ but PCPS often rated their own knowledge as insufficient. ${ }^{3,8,9}$ Many studies have also stressed that recommendations were not satisfactorily applied by general practitioners, ${ }^{7,10-12}$ especially with regard to the early recognition of AD. ${ }^{13}$ Indeed, the number of new cases detected in general practice is below the epidemiological figures based on rates of incidence and prevalence in the general population in Europe. The reasons identified to explain this underdiagnosis are the lack of simple tests, difficulties in disclosing the diagnosis, difficulties in managing behavioural and psychological symptoms of dementia (BPSD) and a lack of time. . $^{7,14-16}$
In recent years, numerous guidelines on detecting the early onset of dementia, diagnostic management, disclosure, pharmacological and non-pharmacological treatment and follow-up have been developed. These guidelines are not always specifically addressed to PCPS and often propose collaboration with specialists and community professionals. ${ }^{1,2,17-20}$ Moreover, one study has underlined the complexity of recommendations for help-seeking in the management of dementia. ${ }^{20}$

Nevertheless, it seems very important for PCPS to be aware of early detection issues. ${ }^{2}$ It has notably been demonstrated that a memory complaint expressed to the PCP is a risk factor for AD. ${ }^{21}$ Therefore, the importance of memory complaints should not be underestimated in clinical practice. Some studies have focused on the need to improve the quality of dementia screening in primary care. ${ }^{22-25}$

While underdiagnosis of $A D$ is certainly an issue to consider, so is underdisclosure. ${ }^{26,27}$ In many studies, PCPS felt uncomfortable disclosing the diagnosis to both the patient and the family care-giver. ${ }^{7,28,29}$ The studies on the attitudes or practice of PCPS concluded that almost half of PCPS are in favour of diagnosis disclosure while the other half are not. ${ }^{30}$ The absence of disclosure or vague information may be poorly received by the patient and his or her family. ${ }^{31}$ For some authors, disclosure to patient and family should be carried out by both the specialist and the PCP.

The pharmacological treatment of dementia is also considered by PCPs as one of the major obstacles in the management process. As a matter of fact, some physicians and other health professionals consider that the diagnosis of AD may not be necessary, considering the lack of curative treatments and the stress related to the 
diagnosis. ${ }^{16,32}$ In the majority of countries, only specialist physicians (neurologists, psychiatrists, geriatricians and physicians with a qualification in geriatrics) may write the initial prescription. ${ }^{33}$ Currently, in many European countries the general practitioner can renew or interrupt symptomatic treatment and it is his or her duty to monitor its tolerance and efficacy. The therapeutic objectives should be explained to the patient and his or her care-giver by the $\mathrm{PCP},{ }^{34}$ who should also explain the benefits expected from the pharmacological treatment. ${ }^{35}$ The role of the PCP in therapeutic management exceeds the framework of pharmacological treatment. Indeed, with regard to non-pharmacological treatment, the role of the PCP is above all to set up support services and, of course, to ensure follow-up.

First of all, management of a patient's co-morbid conditions is one of the major roles of the PCP. ${ }^{36}$ The general objectives of the follow-up plan of $A D$ patients are the detection, prevention and treatment, when possible, of complications (falls, malnutrition, BPSD), based on a global assessment. ${ }^{1,2,37}$ The care and assistance plan will be truly effective only if the PCP facilitates its application with the aim of detecting, preventing and treating complications as soon as they appear in order to reduce their impact on the patient and his or her relatives. ${ }^{37}$ The follow-up plan may be tailored to the individual case in conjunction with a specialist evaluation every six months in order to provide the PCP with all the information necessary for follow-up; a frequency of every one to three months depending on the stability of the symptoms, the severity of the disease and co-morbidities is proposed in many European guidelines. The members of the European Alzheimer's Disease Consortium have put forward propositions concerning patient follow-up based on the French PLASA study, a randomised controlled interventional study of 1,120 patients with AD. ${ }^{38}$ The PCP must first ensure that the diagnosis has been disclosed and basic education on AD provided. Then, at each visit, the physician needs to evaluate cognitive, functional and nutritional status. It is also essential to evaluate behavioural changes, gait and balance disorder, co-morbid diseases and the tolerance/efficacy of drugs. ${ }^{38,39}$ Prevention of crisis situations such as admission to an institution and 'emergency' hospitalisation is one of the major goals of any follow-up plan. The management of $A D$ patients in crisis situations is a dynamic and time-consuming three-sided relationship between the family care-giver, the demented patient and the family physician.

In the event of BPSD and after initiating non-pharmacological measures - in particular environmental measures - the PCP may be led to prescribe psychotropic treatments. It should be noted that antipsychotic drugs must be reserved for specific situations and used in short courses at a low dose, with frequent reassessment of the risk-benefit ratio. ${ }^{40}$

Monitoring of the patient's nutritional status is also an important part of follow-up. ${ }^{41}$ If the patient has weight loss $>2 \mathrm{~kg}$ over the previous three months, or more than $4 \%$ in one year, the PCP should look for a somatic cause and, if none is found, they should advise an enriched diet. ${ }^{42}$ Weight loss is often accompanied by complications such as sarcopenia and falls, which are associated with a higher risk of institutionalisation and mortality. ${ }^{43,44}$ In the event of falls, after a physical or iatrogenic cause has been sought, the patient should be encouraged to walk for 30 minutes every day or three times a week, preferably with the care-giver or, if this is not possible, with the help of a physiotherapist. ${ }^{45}$ The patient's home should be adapted to make movement and walking easier and to reduce the risk of falls. The physical and emotional health status of the care-giver may also be appraised to prevent care-giver exhaustion. ${ }^{46}$ The PCP must be able to recognise distress in care-givers and to evaluate their physical state. The scientific literature supports creating a close relationship with care-givers of AD patients. ${ }^{17.47}$ The PCP needs to estimate the need for home support or respite care (day care centres, temporary stay in a nursing home). PCPS often report a lack of information on support services. ${ }^{48}$ Moreover, support services are generally underused by PCPS, especially in the early stages of the disease, with large variations between countries, notably in Europe. ${ }^{33}$ However, many authors have underlined that the PCP should be familiar with support services, in particular the respite facilities available (day care centres, adult care centres, temporary stay in a nursing home, respite care at home) and also home support services (personal assistance, home help supports). Finally, in all cases collaboration with specialist physicians (neurologists, geriatricians or psychiatrists) is needed; furthermore, a recent work has shown that PCPS are seeking a more cohesive form of interdisciplinary dementia care..$^{48}$

Considering these issues, studies have focused on how to improve the management of $A D$ in primary care practice. ${ }^{49,50}$ The need for better education and training programmes for PCPS has been demonstrated in both the early diagnosis and management of AD. ${ }^{6,51}$ Indeed, sufficient knowledge is one of the prerequisites for adequate dementia management. Training programmes have been developed in most European countries, and relevant educational projects now exist for PCPS. ${ }^{6.52}$ Many of these educational approaches are effective in improving detection rates in dementia. ${ }^{53}$ Indeed, it is essential to train PCPS because their intervention is complex at all levels: they are expected to detect the early onset of dementia, disclose the diagnosis, co-ordinate home care, follow through treatment issues, provide basic education to the care-giver and stay involved in the care process. PCPS have a duty to keep their professional practices and skills up to date, by various means. They must have optimal initial knowledge about the disease and then undergo continuous training in order to progress their professional skills. Considering the likely future prevalence of AD, PCPS will be increasingly confronted with the problems raised by the disease. Dementia in general and $A D$ in particular will have a large impact on the health and healthcare needs of northern countries. For these reasons, it is essential to clearly define the role of primary care providers and to improve their knowledge about the disease and related guidelines..$^{20}$

In conclusion, PCPs must follow the general objectives of identifying dementia and allowing early diagnosis, disclosing diagnosis to both the patient and his or her family, preventing and treating, if possible, the complications of AD (falls, malnutrition, BPSD) and implementing a follow-up plan. ${ }^{1,2,37}$ It is also important for PCPs to develop interactions with specialist physicians and all community professionals who intervene in the management of AD patients. The key role of PCPS is consolidated by the confidence of family care-givers in their skills. Nevertheless, clear and validated guidelines covering all aspects of $A D$ care, from early diagnosis to adequate referrals, should improve the ability of PCPs to support many time- and energy-consuming home care situations. Intervention studies addressing the gaps in the skills of PCPS in dementia management could be helpful in supporting the family care-giver. ${ }^{3}$ Currently, further work, especially the creation of evidence-based practice guidelines, is needed to establish quality indicators for primary dementia care. 
1. Patterson C, Gauthier S, Bergman H, et al., The recognition, assessment, and management of dementing disorders: conclusions from the Canadian Consensus conference on Dementia, Can J Neurol Sci, 2001;28(Suppl. 1):S3-16.

2. Pond $\mathrm{D}, \mathrm{Brodaty} \mathrm{H}$, Diagnosis and management of dementia in general practice, Aust Fam Physician, 2004;33:789-93.

3. Schoenmakers B, Buntinx F, Delepeleire J, What is the role of the general practitioner towards the family caregiver of a community-dwelling demented relative? A systematic literature review, Scand J Prim Health Care, 2009;27:31-40.

4. Hunsaker $A E$, Schmidt $K$, Lingler JH, Discussing dementiarelated behaviors during medical visits for people with Alzheimer's disease, Am J Alzheimers Dis Other Demen. 2010;25:248-54.

5. Kamenski G, Fink W. Maier M, et al., Characteristics and trends in required home care by GPS in Austria: diseases and functional status of patients, BMC Fam Pract, 2006;7:55

6. Tsolaki M, Papaliagkas V, Anogianakis $G$, et al., European Alzheimer Disease Consortium Consensus statement on dementia education and training in Europe, J Nutr Health Aging, 2010;14:131-5

7. Turner S, lliffe S, Downs M, et al., General practitioners knowledge, confidence and attitudes in the diagnosis and management of dementia, Age Ageing, 2004;33:461-7.

8. Hinton L, Franz CE, Reddy G, et al., Practice constraints, behavioral problems, and dementia care: primary care physicians' perspectives, J Gen Intern Med, 2007:22:1487-92.

9. Pentzek M, Abholz HH, Ostapczuk M, et al., Dementia knowledge among general practitioners: first results and psychometric properties of a new instrument, Int Psychogeriatr, 2009;21:1105-15.

10. Waldorff FB, Almind $G$, Mäkelä $M$, et al., Implementation of a clinical dementia guideline. A controlled study on the effect of a multifaceted strategy, Scand I Prim Health Care 2003;21:142-7

11. Musicco M, Sorbi S, Bonavita V, Caltagirone $\mathrm{C}$, Validation of the guidelines for the diagnosis of dementia and Alzheimer's disease of the Italian Neurological Society. Study in 72 Italian neurological centres and 1549 patients, Neurol SC, 2004;25:289-95.

12. Wilcock J, lliffe S, Turner S, et al., Concordance with clinical practice guidelines for dementia in general practice, Aging Ment Health, 2009;13:155-61

13. Maeck L, Haak S, Knoblauch A, Stoppe G, Early diagnosis of dementia in primary care: a representative eight-year followup study in Lower Saxony, Germany, Int J Geriatr Psychiatry 2007:22:23-31.

14. Cahill S, Clark M, O'Connell $H$, et al., The attitudes and practices of general practitioners regarding dementia diagnosis in Ireland, Int J Geriatr Psychiatry, 2008;23:663-9.

15. Hansen EC, Hughes C, Routley G, Robinson AL, General practitioners' experiences and understandings of diagnosing dementia: factors impacting on early diagnosis, Soc Sci Med 2008;67:1776-83.

16. Renshaw J, Scurfield P, Cloke L, Orrell M, General practitioners' views on the early diagnosis of dementia, Br J Gen Pract, 2001:51:37-8.

17. Waldemar G, Dubois B, Emre M, et al., EFNS, Recommendations for the diagnosis and management of Alzheimer's disease and other disorders associated with dementia: EFNS guideline, Eur J Neurol, 2007:14:e1-26.

18. Cummings JL, Frank JC, Cherry D, et al., Guidelines for managing Alzheimer's disease: part I. Assessment, Am Fam
Physician, 2002;65:2263-72

19. Cummings IL, Frank JC, Cherry D, et al., Guidelines for managing Alzheimer's disease: part II. Treatment, Am Fam Physician, 2002:65:2525-34.

20. Werner $P$, Family physicians' recommendations for help-seeking for a person with Alzheimer's disease Aging Clin Exp Res, 2007;19:356-63.

21. Coley N, Ousset PJ, Andrieu S, et al., Memory complaints to the general practitioner: data from the GuidAge study, J Nutr Health Aging, 2008;12:66S-72S.

22. Milne A, Culverwell A, Guss R, et al., Screening for dementia in primary care: a review of the use, efficacy and quality of measures, Int Psychogeriatr, 2008;20:911-26.

23. Trenkle DL, Shankle WR, Azen SP, Detecting cognitive impairment in primary care: performance assessment of three screening instruments, J Alzheimers Dis, 2007:11:323-35.

24. Stoppe G, Maeck L, Early diagnosis of dementia in primary care, Int I Geriatr Psychiatry, 2007;22:498

25. Stoppe G, Haak S, Knoblauch A, Maeck L, Diagnosis of dementia in primary care: a representative survey of family physicians and neuropsychiatrists in Germany, Dement Geriatr Cogn Disord, 2007;23:207-14.

26. Wilkinson D, Stave C, Keohane D, Vincenzino O, The role of general practitioners in the diagnosis and treatment of Alzheimer's disease: a multinational survey, I Int Med Res , 2004;32:149-59.

27. De Lepeleire $\rfloor$, Heyrman $\rfloor$, Diagnosis and management of dementia in primary care at an early stage: the need for a new concept and an adapted procedure, Theor Med Bioeth 1999;20:215-28.

28. Van Hout HP, Vernooij-Dassen MJ, Jansen DA, Stalman WA, Do general practitioners disclose correct information to the patients suspected of dementia and their caregivers? A prospective observational study, Aging Ment Health, 2006;10:151-5.

29. Franz $C E$, Barker $\mathrm{JC}$, Kim $\mathrm{K}$, et al., when help becomes a hindrance: mental health referral systems as barriers to care for primary care physicians treating patients with Alzheimer's disease, Am J Geriatr Psychiatry, 2010;18:576-85.

30. Kaduszkiewicz H, Wiese B, van den Bussche $H$, Self-reporte competence, attitude and approach of physicians towards patients with dementia in ambulatory care: results of a postal survey, BMC Health Serv Res, 2008;6:54.

31. Bamford C, Lamont $\mathrm{S}$, Eccles $\mathrm{M}$, et al., Disclosing a diagnosis of dementia: a systematic review, Int I Geriatr Psychiatry 2004;19:151-69

32. Werner P, Gafni A, Kitai E, Examining physician-patientcaregiver encounters: The case of Alzheimer's disease patients and family physicians in Israel, Aging Ment Health 2004:8:498-504.

33. Reynish E, Cortes F, Andrieu S, et al., ICTUS Study Group, The ICTUS study: A prospective longitudinal observational study of 1,380 AD patients in Europe. Study design and baseline characteristics of the cohort, Neuroepidemiology, 2007;29:29-38

34. Geldmacher DS, Treatment guidelines for Alzheimer's disease: redefining perceptions in primary care, Prim Care Companion I Clin Psychiatry, 2007:9:113-21.

35. Geldmacher DS, Frolich L, Doody RS, et al., Realistic expectations for treatment success in Alzheimer's disease, I Nutr Health Aging, 2006;10:417-29.

36. Naylor MD, Hirschman KB, Bowles KH, et al., Care coordination for cognitively impaired older adults and their caregivers, Home Health Care Serv Q, 2007:26:57-78.

37. Nourhashémi F, Olde Rikkert MG, Burns A, et al.,

Follow-up for Alzheimer patients: European Alzheimer Disease Consortium position paper, J Nutr Health Aging, 2010;14:121-30.

38. Nourhashemi F, Andrieu $S$, Gillette-Guyonnet $S$, et al., PLASA Group, Effectiveness of a specific care plan in patients with Alzheimer's disease: cluster randomised trial (PLASA study), BMJ, 2010;340:C2466

39. Hogan DB, Bailey P, Carswell A, et al., Management of mild to moderate Alzheimer disease and dementia, Alzheimers Dement, 2007;3:355-84.

40. Fitten $L J$, Management of behavioral and psychiatric symptoms in dementia, J Nutr Health Aging, 2006;10:409.

41. Gillette-Guyonnet S, Cortes F, Cantet C, Vellas B, REAL.FR Group, Long-term cholinergic treatment is not associated with greater risk of weight loss during Alzheimer's disease: data from the French REAL.FR cohort, I Nutr Health Aging, 2005;9:69-73

42. Gillette Guyonnet S, Abellan Van Kan G, et al., IANA task force on nutrition and cognitive decline with aging, J Nutr Health Aging, 2007;11:132-52.

43. Andrieu S, Reynish W, Nourhashemi F, et al., Nutritional risk factors for institutional placement in Alzheimer's disease after one year follow-up, J Nutr Health Aging, 2001;5:113-7.

44. Vellas B, Gauthier $\mathrm{S}$, Allain $\mathrm{H}$, et al., Consensus statement on dementia of Alzheimer type in the severe stage, I Nutr Health Aging, 2005;9:330-8.

45. Rolland $\mathrm{Y}$, Abellan van Kan $\mathrm{G}$, Vellas B, Physical activity and Alzheimer's disease: from prevention to therapeutic perspectives, J Am Med Dir AssoC, 2008;9:390-405.

46. Andrieu S, Balardy L, Burden experienced by informal caregivers assisting Alzheimer's patients in the REAL.FR study, Rev Med Interne, 2003;4(Suppl. 3):351s-9s.

47. Lyketsos CG, Colenda CC, Beck C, et al., Task Force of American Association for Geriatric Psychiatry, Position statement of the American Association for Geriatric Psychiatry regarding principles of care for patients with dementia resulting from Alzheimer disease, Am I Geriat Psychiatry, 2006;14:561-72

48. Yaffe MJ, Orzeck P, Barylak L, Family physicians perspectives on care of dementia patients and family caregivers, Can Fam Physician, 2008;54:1008-15.

49. Holle R, Grässel E, Ruckdäschel S, et al., Dementia care initiative in primary practice: study protocol of a cluster randomized trial on dementia management in a genera practice setting, BMC Health Serv Res, 2009;9:91.

50. lliffe $S$, Robinson L, Brayne $C$, et al.; the DeNDRoN Primary Care Clinical Studies Group, Primary care and dementia: 1. diagnosis, screening and disclosure, Int J Geriatr Psychiatry 2009;24:895-901

51. Lionis $\mathrm{C}$, Vlachonikolis J, Chatziarsenis $\mathrm{M}$, et al., Managing Alzheimer's disease in primary care in Crete, Greece: room for improvement, Qual Manag Health Care, 2001;9:16-21.

52. Cherry DL, Hahn C, Vickrey BG, Educating primary care physicians in the management of Alzheimer's disease: using practice guidelines to set quality benchmarks, Int Psychogeriatr, 2009:21(Suppl. 1):S44-52

53. Downs M, Turner S, Bryans M, et al., Effectiveness of educational interventions in improving detection and management of dementia in primary care: cluster randomised controlled study, BMJ, 2006;332:692-6. 